\section{PHYSIOLOGY AT THE BRITISH} ASSOCIATION

THE presidential address in Physiology has appeared in full in Nature (September 14), and the remainder of the sectional proceedings can be summarised under three heads : reports of committees and papers related to them, discussions, and other communications.

\section{Reports of Committees.}

Committee on Anaesthetics.-The report contains four appendices. The first describes the installation of a chloroform-balance for daily use in hospital practice. The detailed instructions by Prof. Waller will be extremely useful for anyone who wishes to establish one of Prof. Waller's instruments. The second appendix contains some estimations of the probable percentage of ether inhaled by the "open" method of ether administration. The third appendix relates the experience gained by the use of a chloroform-balance in the out-patient department of St. George's Hospital, and the fourth is a recapitulation of the effect of recent advances on the practice of anæsthesia.

This report was followed by a paper by Dr. A. Vernon Harcourt, F.R.S., on additions to the use of a chloroform inhaler. As objection had been made to the vacuum principle of the author's chloroform inhaler, he has adapted his ingenious apparatus to work by the plenum system, and also for use with oxygen.

Committee on Dissociation of Oxyhaemoglobin at High Altitudes.- The hydrogen ion concentration of blood can be determined by the percentage saturation of hæmoglobin with oxygen at low pressures of oxygen. Using this method, it was found that at high altitudes the hydrogen ion concentration of the blood was increased.

The remainder of the reports contained information of such detailed nature that it is not possible to give a summary of their contents, but in some cases the work has already been published elsewhere.

\section{Discussions.}

Discussion on Inhibition.--Prof. C. S. Sherrington, F.R.S., opened the discussion by pointing out that it would be of great importance to discover the intimate nature of inhibition. The processes of inhibition are fundamentally the same whether they occur in the central nervous system or in apparently muscular organs such as the heart. He then described many of the phenomena of inhibition as exhibited by rhythmical reflex movements of the limbs. In dealing with the reciprocal action of muscles, it seems necessary to assume, as suggested by Macdonald, that there is an intercalated neurone in the inhibition path. Any after discharge from the muscle, which ought to have finished contracting, would lead to clumsiness in the alternating movements of flexion and extension; but inhibition removes all after discharge. In the same way inhibition diminishes the tonus in muscles antagonistic to those that are contracting. The utility of a common final path is evident, because there cannot be more than one movement going on at the same time; and so long as a path is held by inhibition contraction cannot occur, and vice versa. Examples were shown of double stimulation and algebraical summation of excitation and inhibition in both flexors and extensors. Two antagonists may be in action together, but their activity increases and decreases in reciprocal proportions; hence the smoothness and accuracy of trained movements. The conditions favourable to inhibition are fatigue and administration of chloroform, and those favourable to excitation are increase in the "background" stimulation and administration of strychnine and tetano-toxin. According to circumstances, the same stimulus may give either excitation or inhibition.

Dr. John Tait, rhythmical stimulation of cooled frog's nerve. The Wedensky effect was described, and Frohlich's explanation of the phenomenon was stated. By cooling the nerve a result was obtained similar to that of Wedensky. The effect is greater the greater the degree of cooling, the longer the piece of nerve cooled, and the more rapid the rate of stimulation. Conduction by the nerve is entirely blocked at $-2^{\circ}$ C., and the phenomenon is present near this point. Fatigue favours the effect. Wedensky effect is shown by well-fed, but not by underfed, animals.

NO. 2 I90, VOL. 87 ]
Dr. Keith Lucas, conduction between muscle and nerve with special reference to inhibition. Frohlich's explanation of the Wedensky effect does not hold in homogeneous tissues, as a second stimulus within the refractory period does not prolong the refractory phase. By indirect stimulation it was found that the blocking occurs at the junction between muscle and nerve. The refractory period of nerve is less than that of muscle, and a stimulus sent into the nerve shortly after the end of the refractory period causes a second refractory period. A stimulus to the nerve just after the end of the refractory period is so diminished in strength that it cannot pass the motor end plate. The explanation is that each stimulus to the nerve reduces the response to the succeeding stimulus, and thus all except the first are too weak to pass the resistance of the junction between muscle and nerve; thus there is a single contraction of the muscle with the first stimulus, and no further response, as the stimulation continues. By applying the same processes to the synapses of the central nervous system, an explanation of central inhibition was given. Prof. Waller then spoke, and Prof. Sherrington replied.

Discussion on ventilation in confined quarters, especially in relation to ships. Dr. Leonard Hill, F.R.S., introduced the subject by explaining that under ordinary conditions the percentage of oxygen is never reduced to a dangerous extent, nor is the carbon dioxide increased beyond reasonable limits. The great factor in ventilation is to provide air under suitable conditions to promote evaporation from the skin and stimulate the nerve endings in the skin. ' $\mathrm{He}$ then described experiments showing that circulation of air in a closed chamber produced the same effect as admitting fresh air in promoting a feeling of well-being. A draught is dangerous, as it causes a local cooling, but cooling of the whole surface by evaporation from the skin is beneficial. He described some of the special difficulties met with on board ships, and advocated the wet- and dry-bulb thermometers as a test of the efficiency of ventilation. Fresh air is beneficial, as it dilutes harmful products, such as bacteria.

An abstract furnished by Prof. N. Zuntz, of Berlin, was read. He agreed with Dr. Hill that oxygen and carbon dioxide are not the predominating factors in ventilation, but he pointed out that there might be poisonous gases given off under some conditions. He then showed that unless the carbon dioxide be kept down to the limit usually given as the maximum allowable, the air becomes almost saturated with the moisture given off from the lungs. Therefore the moisture must be kept down by dilution with fresh air or by condensation on cold surfaces. The use of fans will not entirely remove the need for fresh air, but they will improve the working efficiency of the men.

Dr. C. J. Martin, F.R.S., spoke in support of. Dr. Hill's view by referring to the conditions in Australian gold mines.

Fleet-Surgeon Whitelegg gave instances of the difficulties encountered on board battleships, where, of course, the fighting efficiency was the first consideration. He then described some of the precautions taken before men were allowed to enter unventilated spaces. Dr. Hill then replied.

\section{Other Communications.}

Prof. H. J. Hamburger, on the influence of iodoform, chloroform, and other substances dissoluble in fats on pharocytosis. In the absence of the author an abstract of this paper was read. In high dilutions the substances used promoted phagocytosis. This effect is the result of the substances dissolving in the lipoids of the cell wall, whereby the surface tension is lowered. When the surface tension is lowered there is less resistance to an increase of surface, and hence amœboid movements occur more easily.

Dr. J. Tait and Mr. J. A. Hewitt, certain physical questions regarding blood vessels and blood cells. Blood does not adhere to the endothelium of blood vessels. This is associated with a large amount of ether soluble material in the endothelial cells. Coating glass vessels with oil delays coagulation, as it prevents the adhesion to the glass of certain blood cells. Possibly the high bloodblood-vessel surface tension, as shown by non-adherence of 
the blood to the vessel wall, is a factor in preventing coagulation of blood in the vessels. Contact of amcoboid corpuscles with particles of carmine or Indian ink causes phagocytosis if the surface tension between corpuscle contents and particle is less than that between the plasma and particle. When a corpuscle adheres to the wall of a blood vessel it is driven outwards if the surface tension between corpuscle and blood-vessel wall is less than that between corpuscle and plasma, and hence diapedesis occurs. The association of hæmolytic and hæmorrhagic poisons may be due to a lowering of the surface tension causing both processes.

Mr. W. W. Waller, an attempt to obtain photographic records of the emigration of leucocytes. This was illustrated by a number of photographs showing blood vessels with white corpuscles escaping from them. Several interesting points were mentioned, such as a tendency for several corpuscles to escape at the same point, and apparently to form colonies after their escape.

Dr. Hariette Chick and Dr. C. J. Martin, F.R.S., the chemistry of heat coagulation of proteins. Coagulation takes place in two stages, denaturation and agglutination. Denaturation is due to the presence of water, depends on the temperature, and is an exponential function of the concentration. The temperature coefficient is remarkably high. Egg albumin differs from hremoglobin owing to a change in reaction during coagulation, but by using boric acid to keep the hydrogen ion concentration constant the egg albumin then behaves like hæmoglobin. Increase of acidity favours denaturation. Agglutination depends on the concentration of hydrogen ions. Three factors, namely, surface tension, electrical charge, and velocity of Brownian movement seem to regulate the agglutination.

Prof. Freundlich spoke on this communication, referring to the importance of such investigations into the processes of coagulation.

Di. W. N. F. Woodland, recent views concerning the physiology of gas production in connection with the gas bladder of bony fishes. The structure of the rete mirabile duplex is concerned with the secretion of oxygen. The composition of the gas varies in different species. The pressure of any particular gas may be greater than that in the blood stream, and hence there must be some process of secretion. Fish which change their depth rapidly secrete oxygen to compensate for the effects of pressure. A weighted fish rises after some time, mainly due to increase of oxygen in the swim bladder. It has been stated that a toxin is formed which causes hæmolysis of the red blood corpuscles, but none was found as the result of activity, nor, as previously stated, were gas bubbles found in the secreting cells. The author urged physiologists to undertake the study of the process of oxygen secretion.

Prof. J. S. Macdonald and Dr. J. E. Chapman, heat production and body temperature during rest and work. By means of the calorimeter at Sheffield the heat production of a fasting man was determined at rest and then during the performance of work. Heat output lags behind heat production owing to a rise of body temperature, which stores a certain amount of heat. The lighter the clothing the more nearly the heat output keeps pace with the heat production. Fatigue is not shown in the record of heat output, but it is shown in the rate of cycling.

Dr. H. E. Roaf, carbon dioxide output during decerebrate rigidity. The carbon dioxide output was measured during decerebrate rigidity, and then after abolishing the rigidity. Abolishing the rigidity by curare or by cutting the motor nerves did not lower the carbon dioxide output. Hence decerebrate rigidity differs from ordinary muscular contraction, as there is no increased production of carbon diovide during rigidity.

Dr. F. W. Edridge-Green, the frequency of colourblindness in males. The percentage of colour-blind men has been underestimated. The author finds at last 6 per cent. are colour-blind, and that 25 per cent. have diminished colour-vision.

Prof. G. J. Stokes, paramnesia. The author suggests that the same idea may reach the brain by two different routes, one passing through a greater number of synapses, and thus arriving after the other. Hence in certain cases a feeling that the incident is not new, although it could not possibly have happened before.
Miss May Yates, the nutritive value of whole meal and white bread. This was a correction of some statements made in a recent Local Government Board report. It was claimed that the report did not correctly compare the nutritive value of white flour and flour without removal of the germ and bran.

Prof. A. D. Waller, F.R.S., read an interesting historica paper reviewing the documentary evidence of the discovery of the distinction between motor and sensory nerves.

It was an unfortunate coincidence that the two foreign guests who had accepted invitations as representatives or physiology should at the last moment have been prevented from attending the meeting. Apart from this, the meering was an agreeable and interesting one for physiologists.

\section{AGRICULTURE AT THE BRITISH ASSOCIATION.}

THE outstanding event this year was the elevation of agriculture to the position of a full section; henceforward agriculture comes definitely within the purview of the British Association, and permanently figures as Section M. The increasing output of work by investigators in this country fully justifies this step, while the great interest always shown in agricultural matters by the members of the association encourages the hope that the new section will at least contribute its share to the attractiveness of the meetings.

The problems presented by soils, crops, and animals are so complex that agricultural investigators are bound to keep in close touch with workers in pure science in order that their methods and conclusions may be critically examined. At the British Association meetings more than anywhere else such critical discussions are possible, and in permanently arranging for them the association is fulfilling the first of its declared objects- " to give a stronger impulse and a more systematic direction to scientific inquiry.",

The president's address dealt broadly with the application of genetics to the problems of agriculture and horticulture (see NATURE, September 21), and several of the papers dealt with special aspects of this subject. In an interesting communication Mr. C. C. Hurst discussed the genetics of horse-breeding. Chestnut coat colour is recessive to bay and brown; consequently chestnut horses always breed true when mated together, notwithstanding their bay and brown ancestors. Bays and browns, however, are of two kinds, one throwing chestnuts, the other not. Grey is dominant to bay, brown, and chestnut, but since grey $x$ grey matings are rare in England, English grey thoroughbreds are nearly all heterozygous, throwing bays, browns, or chestnuts; a homozygous grey is, however, known in Germany which throws nothing but greys. In certain strains a partial coupling is observed between coat colour and racing power, bay and brown descendants of St. Simon being much better racers than the chestruts. There is apparently a partial tripling of brown coat colour, high racing power, and female sex in St. Simon's own offspring.

Prof. Wilson described his studies of the inheritance of milk yield in cattle, the earlier accounts of which have attracted a good deal of attention. After eliminating abnormalities due to time of calving, period of lactation, food, shelter, and age of the animal, it is found that fullsized mature cows fall into three grades, giving, respectively, 500 to 600,650 to 850 , and about rooo gallons of milk a year. The two extreme grades are approximately pure, while the middle grade is a hybrid.

A different tvpe of problem was dealt with by $\mathrm{Mr}$. W. J. Backhouse. A systematic inquiry was undertaken into the gametic composition of our common plums with the view of putting the raising of new plums on a scientific basis. At the height of the flowering period the flowers of certain plums were carefully hand-pollinated with their own pollen. Some varieties proved remarkably self-fertile, the flowers setting very well to fruit. Other varieties, however, proved self-sterile, and set absolutely nothing. It is understood that these interesting observations are being followed up.

A useful day was spent in discussing the bacterial NO. 2 I90, VOL. 87] 